Progressive Physics Journal
Volume 2, Nomor 1, Juni 2021
ISSN2722-7707 (online)
http://jurnal.fmipa.unmul.ac.id/index.php/ppj/index

\title{
ANALISIS KOEFISIEN SERAPAN (ABSORPSI) KEBISINGAN PADA BAHAN KAYU (Triplek, Papan Kayu, dan Kalsiboard)
}

\author{
Siti Istikhomah ${ }^{2}$, Syahrir $^{1,3,}{ }^{*}$, Adrianus Inu Natalisanto ${ }^{1,3}$ \\ ${ }^{1}$ Jurusan Fisika, FMIPA, Universitas Mulawarman \\ ${ }^{2}$ Laboratorium Elektronika dan Instrumentasi, Universitas Mulawarman \\ ${ }^{3}$ Laboratorium Fisika Dasar, Universitas Mulawarman \\ JI. Gunung Kelua No. 4, Samarinda, Kalimantan Timur,Indonesia \\ $\left({ }^{*}\right)$ e-mail: iistikomah825@gmail.com
}

\begin{abstract}
Noise is an unwanted sound by humans and is an environmental factor that can negatively affect health. To solve the noise problem, different method are made to reduce the noise level. One of the example is by making a house wall using wood materials that have damping and sound absorption standards. In this study the wood materials that were used such as plywood, wooden plates and calsiboard. The focus of this study was to see the appropriate wood materials as a damping material and to calculate the value of the sound absorption factor in wood materials. The research analysis of coefficient of sound absorption was utilized experimental methods and the data were used are raw data. The data are processed by the formula of coefficient of sound absorption and the end result of this study are in the shape of graph by the coefficient of sound absorption. Based on the results of the study of sound absorption coefficients for types 3 of wood materials, it can be noted that the shape of the graph states that the value of the lower sound absorption coefficients is likely to be at a small frequency value. Then, for the graph, the value of the higher sound absorption coefficients tends to be of high frequency value. In fact, when the graph are viewed as whole size, high and low value of sound absorption coefficients on the graph is not line with the increase in frequency value. This can be happen because of the environmental factors that affect.
\end{abstract}

Kata Kunci: Damping, Noise, Wood Material.

\section{PENDAHULUAN}

Manusia merupakan makhluk yang mempunyai beberapa alat indera, seperti indera penglihatan, indera pendengaran, indera perasa, dan lain-lain. Alat-alat indera tersebut biasanya digunakan sebagai pendeteksi beragam kebendaan yang bersifat visual maupun auditif terhadap kehidupan sosial dalam lingkungan sekitarnya. Adanya alat-alat indera tersebut terkadang manusia mengalami berbagai permasalahan, seperti pada indera pendengaran yang berkaitan dengan bunyi. Bunyi sering digunakan manusia sebagai alat komunikasi ataupun media informasi yang bersifat abstrak. Bunyi juga dapat berasal dari berbagai sumber, seperti bunyi kendaraan transportasi maupun bunyi mesin pada pabrik sehingga terjadilah permasalahan yang disebut kebisingan.

Kebisingan merupakan suara yang tidak dikehendaki oleh manusia dan merupakan faktor lingkungan yang dapat berpengaruh negatif terhadap kesehatan. Untuk mengatasi permasalahan dan terjadinya kebisingan ini maka dilakukan berbagai upaya untuk mengurangi tingkat kebisingan, seperti pembuatan peredaman pada dinding rumah atau suatu bangunan. 
Salah satu contoh bahan peredaman yaitu bahan yang terbuat dari bahan kayu. Bahan kayu atau bahan akustik dapat berupa papan kalsiboard, papan triplek dan papan kayu. Bahan tersebut selain harganya lebih terjangkau juga mudah untuk didapatkan. Bahan kayu yang digunakan mempunyai ketebalan dan kriteria peredaman, agar dapat meredam suatu gelombang bunyi.

Gelombang bunyi melewati suatu medium fisik maka intensitas bunyi akan ditempuh terhitung mulai terjadinya sumber bunyi tersebut dan peristiwa ini dikenal sebagai atenuasi. Bunyi mengalami atenuasi sedangkan medium menerima energi akustik sehingga menjadi panas. Peristiwa terjadinya perubahan menjadi panas ini merupakan bentuk atenuasiyang dikenal sebagai penyerapan bunyi [1]

Menurut Penelitian dari [1], Meneliti tentang koefisien serap bunyi pada papan partikel dari bahan serbuk kayu kelapa. Penelitiannya menggunakan bahan papan partikel dibuat dengan mencampur serbuk kayu kelapa dengan tepung kanji, dicetak dan dikeringkan. Sampel berbentuk silinder. Bahan dibuat dengan ketebalan 1,15 cm; 1,95; cm; 2,95 cm; dan 4,05 cm. Hasil penelitiannya menunjukkan bahwa ketebalan sampel mempengaruhi nilai koefisien serap bunyi yaitu pada frekuensi $600 \mathrm{~Hz}$. Koefisien serap bunyi semakin menurun dengan bertambahnya ketebalan papan partikel. Nilai koefisien serap bunyi bahan diukur dengan menggunakan rumus koefisien serap bunyi.

Penelitian yang dilakukan oleh [2], tentang penentuan koefisien absorpsi dan impedensi material akustik resonator panel kayu lapis berlubang dengan menggunakan metode tabung. Sampel yang digunakan yaitu, material beton dan kayu lapis. Hasil penelitiannya menjelaskan bahwa koefisien absorpsi bunyi beton 0,25 pada frekuensi $2000 \mathrm{~Hz}$. Setelah dilapisi resonator panel kayu lapis meningkat menjadi 0,51. Beton yang dilapisi resonator panel kayu lapis berlubang didapatkan koefisien absorpsi bunyi tertinggi yaitu, 0,61. Frekuensi yang digunakan yaitu, $500 \mathrm{~Hz}, 1000 \mathrm{~Hz}, 2000 \mathrm{~Hz}, 4000 \mathrm{~Hz}$ dan $8000 \mathrm{~Hz}$.

Menurut penelitian sebelumnya [3], hasil pengujian penyerapan bunyi diperoleh dari perbandingan intensitas sebelum dan setelah melewati medium. Perambatan gelombang yang melalui bidang pembatas akan mengalami pemantulan, penyerapan dan transmisi. Besar kecilnya nilai koefisien serap selain bergantung pada frekuensi bunyi dan karakteristik material pembatas bergantung pada sudut jatuh pada gelombang bunyi.

Oleh karena itu, berdasarkan penjelasan dari latar belakang yang telah diuraikan, penelitian ini mengembangkan bahan akustik yang digunakan dengan bahan kayu. Bahan kayu yang digunakan yaitu, triplek, papan kayu, dan kalsiboard. Frekuensi yang digunakan pada penelitian ini yaitu $1000 \mathrm{~Hz}-3000 \mathrm{~Hz}$. Bahan kayu masing-masing mempunyai ketebalan dan karakteristik yang berbeda. Bahan tersebut akan dilihat nilai koefisien serap bunyinya dengan menggunakan rumus koefisien absorpsi bunyi dan untuk mengetahui efisiensi dari bahan triplek, papan kayu dan kalsiboard.

\section{TINJAUAN PUSTAKA}

\section{Gelombang dan Bunyi}

Gelombang merupakan usikan yang terjadi akibat perambatan energi osilasi. Gelombang berdasarkan arah rambatannya dibagi menjadi dua, yaitu gelombang transversal dan gelombang longitudinal. Gelombang transversal adalah gelombang yang arah getarannya tegak lurus terhadap arah rambatnya, sedangkan gelombang longitudinal adalah gelombang yang memiliki arah getarannya yang sejajar dengan arah rambatnya. Dalam mengungkapkan fenomena gelombang, ada banyak sekali permasalahan yang dikaji lebih dalam. Salah satunya adalah mengenai atenuasi gelombang. Dalam sistem transmisi gelombang, misalnya dalam pengiriman sinyal, biasanya sinyal yang diterima pada receiver tidaklah selalu sama dengan yang ditransmisikan. Hal ini diakibatkan banyaknya noise yang ditemui selama penjalaran sinyal 
tersebut. Atenuasigelombang adalah gejala pelemahan sinyal transmisi seiring dengan pertambahan jarak dari transmitter ke receiver [4].

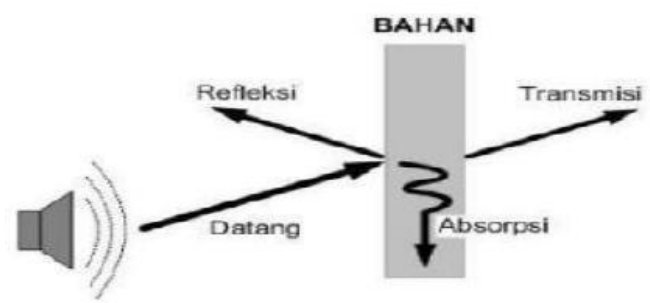

Gambar 1. Peristiwa terjadinya refleksi, absorpsi, refraksi dan transmisi pada suatu benda (Sumber; Ikhsan, 2016)

\section{Material Akustik}

Kata akustik berasal dari bahasa Yunani yaitu, akoustikos yang artinya segala sesuatu yang bersangkutan dengan pendengaran pada suatu kondisi ruang yang dapat mempengaruhi mutu bunyi. Akustik adalah ilmu yang mempelajari tentang suara atau bunyi. Akustik dalam arsitektur sering dibagi menjadi akustik ruang yang menangani bunyi yang dikehendaki dan control kebisingan yang menangani bunyi yang tak dikehendaki. Material akustik adalah material teknik yang fungsi utamanya adalah untuk menyerap suara/bising. Material akustik adalah suatu bahan yang dapat menyerap energi suara yang datang dari sumber suara [5].

Menurut penelitian dari [6], semua bahan dapat menyerap energi suara. Besarnya energi suara yang diserap berbeda-beda untuk tiap bahan. Energi suara tersebut dikonversi menjadi energi panas, yang merupakan hasil dari fiksi dan resistansi dari berbagai material untuk bergerak dan berdeformasi. Peredaman suara merupakan suatu hal yang penting didalam desain akustik dan dapat diklasifikaskan menjadi 4 bagian yaitu:

1. Material berpori;

2. Membran penyerapan;

3. Rongga penyerap;

4. Manusia dan furnitur.

\section{Definisi Kebisingan}

Kebisingan merupakan bunyi atau suara yang tidak dikehendaki dan dapat mengganggu kesehatan serta kenyamanan lingkungan yang dinyatakan dalam satuan decibel (dB). Kebisingan juga dapat didefinisikan sebagai bunyi yang tidak disukai, suara yang menganggu atau bunyi yang menjengkelkan. Berdasarkan keputusan menteri tenaga kerja, kebisingan adalah suara yang tidak dikehendaki yang bersumber dari alat-alat, proses produksi yang pada tingkat tertentu dapat menimbulkan gangguan kesehatan dan pendengaran. Kebisingan di atas tingkat yang aman dapat menyebabkan sejumlah dampak bagi kesehatan, yaitu: gangguan psikolog, meningkatkan emosi, tidur terganggu, ketidakmampuan untuk berkonsentrasi dan hilangnya produktivitas. Selain mempengaruhi kesehatan, faktor kebisingan tersebut dapat mempengaruhi proses kerja maupun hasil kerja pada suatu perusahaan. Terlebih lagi apabila sedang turun hujan, tentu kebisingan dapat berpengaruh dalam kualitas pembicaraan dalam ruang [5].

Telinga atau pendengaran manusia standar tanggap terhadap bunyi antara jangkauan frekuensi audio sekitar 20 sampai $20.000 \mathrm{~Hz}$. Pada umumnya bunyi (pembicaraan, musik, dan bising) terdiri dari banyak frekuensi, yaitu komponen-komponen frekuensi rendah, tengah dan medium. Frekuensi standar yang dapat dipilih secara bebas sebagai wakil yang penting dalam akustik lingkungan adalah 125, 250,500, 1000, 2000, dan $4000 \mathrm{~Hz}$ atau 128, 256, 512, 1024, 
2048, dan $4096 \mathrm{~Hz}$. Perbandingan antara energi suara yang diserap oleh suatu bahan dengan energi suara yang datang pada permukaan bahan tersebut disebut sebagai koefisien absorpsi. Koefisien absorpsi merupakan salah satu parameter penting dalam penentuan sejauh mana suatu bahan dapat menyerap/mereduksi bunyi dan kualitas dari bahan peredam suara ditunjukkan dengan nilai koefisien serapan [7].

\section{Koefisien Penyerapan (Absropsi) Bunyi}

Penyerapan bunyi merupakan perubahan energi menjadi bentuk lain, biasanya panas yang telah melewati suatu permukaan bahan. Selain itu juga berbentuk bunyi yang melewati permukaan bahan, sehingga bunyi yang telah melewati bahan tersebut akan mengalami berubahan menjadi lebih kecil. Prinsip penyerapan bunyi terjadi pada saat suatu bahan atau material yang digunakan kehilangan energi ketika suatu gelombang bunyi menabrak dan dipantulkan dari suatu perbuahan bahan atau material, sehingga bunyi tersebut akan ditransmisikan, diserap, dan dipantulkan. Namun besarnya jumlah bunyi yang diserap, dipantukan dan ditrasnmisikan tergatung pada jenis bahan atau material yang digunakan [8].

Menurut penelitian sebelumnya [9], persamaan koefisien penyerapan bunyi dapat kita selesaikan menggunakan uraian dari koefisien atenuasilinier, suatu bahan serap bunyi tergantung pada jenis bahan dengan penahan bunyi mengikuti fungsi eksponensial. Bila bunyi dengan intensitas bunyi I menembus bahan setebal $x \mathrm{~cm}$, maka akan terjadi pengurangan bunyi sebanyak $d l$, dan ditulis dalam persamaan:

$$
d I=-I \cdot \alpha \cdot d x
$$

\section{dengan:}

$d l=$ perubahan di dalam intensitas $(\mathrm{dB})$

I = intensitas awal (dB)

$\alpha \quad=$ koefisien serap bunyi $\left(\mathrm{cm}^{-1}\right)$

$d x \quad=$ perubahan ketebalan material $(\mathrm{cm})$

dengan cara integrasi, persamaan (1) menjadi,

diubah menjadi,

$$
I=I_{0} e^{-\alpha x}
$$

Dengan:

I = intensitas bunyi setelah melewati sampel (dB)

$I_{0}=$ intensitas bunyi sebelum melewati sampel $(\mathrm{dB})$

$\alpha=$ koefisien penyerapan bunyi $\left(\mathrm{cm}^{-1}\right)$

$x \quad=$ ketebalan rintangan atau sampel penyerapan bunyi $(\mathrm{cm})$

[8].

\section{Hubungan Antara Koefisien Absorpsi Bunyi dengan Frekuensi}

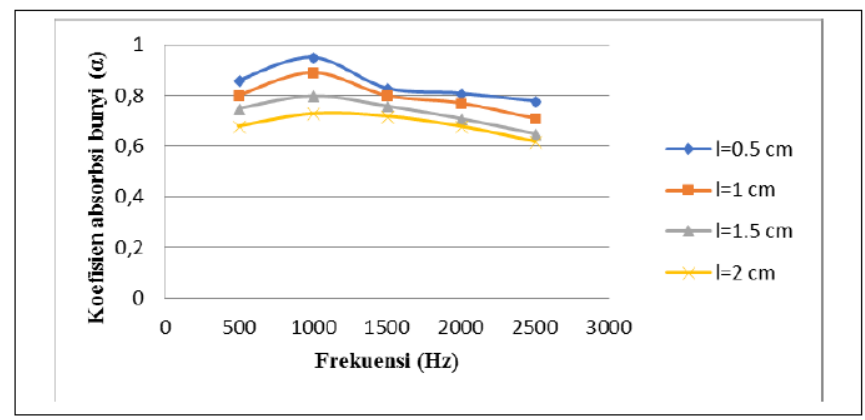

Gambar 3. Hubungan Antara Koefisien Absorpsi Bunyi dengan Frekuensi (Sumber; Yuliantika, 2018\} 
Hubungan antara koefisien absorpsi bunyi dengan frekuensi yaitu, jika nilai frekuensi kecil maka, nilai koefisien absorpsi bunyinya akan semakin besar begitu juga sebaliknya. Namun hal itu juga dipengaruhi oleh ketebalan dari bahan yang digunakan jika bahan yang digunakan semakin tebal maka nilai koefisien absorpsi bunyinya semakin kecil atau rendah dan begitu juga sebaliknya. Koefisien absorpsi bunyi dapat mengalami kenaikan pada bahan atau material akustik yang tipis dikarenakan bahannya yang berpori sehingga gelombang bunyi mudah masuk dan diserap, sedangkan nilai koefisien absorpsi bunyi mengalami penurunan pada bahan atau material akustik yang tebal dikarenakan bahannya lebih padat sehingga gelombang bunyi sulit untuk masuk dan diserap. Peristiwa tersebut dilihat pada Gambar 3 yaitu, hubungan antara koefisien absorpsi bunyi dengan frekuensinya [10].

\section{METODE PENELITIAN}

\section{Waktu dan Tempat Penelitian}

Penelitian ini dilaksanakan pada bulan Maret 2020 sampai dengan bulan Maret 2021 bertempat di Laboratorium Elektronika dan Instrumentasi, Fakultas Matematika dan IImu Pengetahuan Alam, Kampus Gunung Kelua, Universitas Mulawarman, Kota Samarinda, Provinsi Kalimantan Timur. Data penelitian ini menggunakan data primer dengan menggunakan metode eksperimen. Data ini didapatkan dari pengambilan data absorpsi bunyi.

\section{Alat dan Bahan Penelitian}

Penelitian ini menggunakan alat-alat yaitu, mobile phone yang telah di instal aplikasi signal generator dan aplikasi sound level meter yang digunakan sebagai sumber bunyi $\left(I_{0}\right)$ dan receiver (transmisi $\left(I_{T}\right)$, reflaksi $(I r)$, dan refleksi $\left(I_{s}\right)$ ), tiang statif yang digunakan sebagai tempat mobile phone dan tempat bahan penelitian yang digunakan sebagai tempat bahan yang terbuat dari seng, tempat bahan ini dibuat bertujuan agar sumber bunyi tidak langsung ke receiver, disajikan pada Gambar 4. Bahan yang digunakan pada penelitian ini yaitu, triplek dengan ukuran ukuran $p=24,5 \mathrm{~cm}, l=16 \mathrm{~cm}$, dan ketebalan $=0,5 \mathrm{~cm}$, papan kayu dengan ukuran $p=24 \mathrm{~cm}, l=16 \mathrm{~cm}$ dan ketebalan $=1 \mathrm{~cm}$, dan kalsiboard ukuran $p=24,5 \mathrm{~cm}, l=$ $16 \mathrm{~cm}$, dan ketebalan $=0,5 \mathrm{~cm}$. Ukuran yang digunakan telah disesuaikan dengan ukuran tempat bahan penelitian.



Gambar 4.Tempat Bahan Penelitian 


\section{Tahap Pengambilan Data}

Adapun langkah-langkah pengambilan data yatiu bahan triplek, papan kayu dan kalsiboard dipotong sesuai ukuran tempat bahan penelitian, kemudian bahan yang telah dipotong ditempatkan pada tempat bahan penelitian yang telah dirancang. Satu buah mobile phone yang telah terinstall signal generator sebagai sumber bunyi ditempatkan di depan bahan dengan jarak $25 \mathrm{~cm}$, dua buah mobile phone sebagai receiver yang telah terinstall sound level meter untuk mengukur bunyi awal dan bunyi refleksi (dipantulkan), ditempatkan di sebelah kanan dan kiri sumber bunyi dengan jarak dari bahan $25 \mathrm{~cm}$ dan jarak antar sumber bunyi 10 $\mathrm{cm}$, dan dua buah mobile phone sebagai receiver yang telah terinstall sound level meter untuk mengukur bunyi yang melewati sampel atau bunyi transmisi dan bunyi refraksi ditempatkan di bagian sisi depan sumber bunyi. Jarak antara sampel dengan kedua receiver tersebut adalah 25 $\mathrm{cm}$. Sumber bunyi dibunyikan dengan frekuensi yang bervariasi. Pada penelitian tersebut frekuensi yang digunakan dimulai dari frekuensi $1000 \mathrm{~Hz}$ hingga $3000 \mathrm{~Hz}$ kemudian dinaikan $100 \mathrm{~Hz}$ per setiap pengambilan data. Pengambilan data dilakukan 5 kali perulangan untuk setiap kenaikan frekuensi kemudian dicatat hasil pengukuran pada semua receiver.

\section{Tahap Perhitungan Data}

Metode perhitungan ini digunakan untuk mengetahui nilai koefisien absorpsi bunyi pada bahan triplek, papan kayu, dan kalsiboard. Rumus yang digunakan pada perhitungan yaitu, rumus koefisien absorpsi bunyi dan data yang dihitung adalah data transmisi atau bunyi yang diteruskan. Pada rumus koefisien absorpsi bunyi melibatkan ketebalan bahan, bunyi awal dan bunyi yang telah melewati bahan penelitian agar didapat nilai koefisien absorpsi bunyinya. Hasil nilai koefisien absorpsi bunyi yang telah diolah kemudian disajikan dalam bentuk grafik.

\section{HASIL DAN PEMBAHASAN}

Setelah dilakukan analisis data maka diperoleh nilai koefisien Absorpsi Bunyi $(\alpha)$ transmisi pada bahan kayu triplek, papan kayu dan kalsiboard yang disajikan dalam Tabel 2 sebagai berikut.

Tabel 2.Nilai Koefisien Absorpsi Bunyi Transmisi pada Kayu Triplek, Papan Kayu dan Kalsiboard

\begin{tabular}{cccccc}
\hline No & $\begin{array}{c}\text { Frekuensi } \\
(\mathrm{Hz})\end{array}$ & Amplitudo & $\begin{array}{c}\alpha\left(\mathrm{cm}^{-1}\right) \\
(\text { Triplek })\end{array}$ & $\begin{array}{c}\alpha\left(\mathrm{cm}^{-1}\right) \\
\text { (Papan Kayu })\end{array}$ & $\begin{array}{c}\alpha\left(\mathrm{cm}^{-1}\right) \\
(\text { Kalsiboard })\end{array}$ \\
\hline 1 & 1000 & 4 & 0,189 & 0,242 & 0,308 \\
2 & 1100 & 4 & 0,183 & 0,155 & 0,257 \\
3 & 1200 & 4 & 0,242 & 0,171 & 0,260 \\
4 & 1300 & 4 & 0,600 & 0,209 & 0,298 \\
5 & 1400 & 4 & 0,238 & 0,131 & 0,284 \\
6 & 1500 & 4 & 0,239 & 0,135 & 0,288 \\
7 & 1600 & 4 & 0,342 & 0,119 & 0,248 \\
8 & 1700 & 4 & 0,422 & 0,237 & 0,182 \\
9 & 1800 & 4 & 0,552 & 0,255 & 0,229 \\
10 & 1900 & 4 & 0,519 & 0,350 & 0,205 \\
11 & 2000 & 4 & 0,334 & 0,350 & 0,289 \\
12 & 2100 & 4 & 0,396 & 0,119 & 0,231 \\
13 & 2200 & 4 & 0,605 & 0,244 & 0,372 \\
14 & 2300 & 4 & 0,215 & 0,332 & 0,466 \\
15 & 2400 & 4 & 0,293 & 0,179 & 0,294 \\
16 & 2500 & 4 & 0,217 & 0,072 & 0,179
\end{tabular}




\begin{tabular}{llllll}
17 & 2600 & 4 & 0,171 & 0,140 & 0,371 \\
18 & 2700 & 4 & 0,181 & 0,088 & 0,336 \\
19 & 2800 & 4 & 0,254 & 0,082 & 0,267 \\
20 & 2900 & 4 & 0,275 & 0,111 & 0,198 \\
21 & 3000 & 4 & 0,507 & 0,102 & 0,211 \\
\hline
\end{tabular}

Berdasarkan data tabel nilai koefisien absopsi bunyi transmisi di atas maka di dapat hasil grafik dari bahan triplek dengan ketebalan 0,4 cm pada Gambar 5, sebagai berikut.

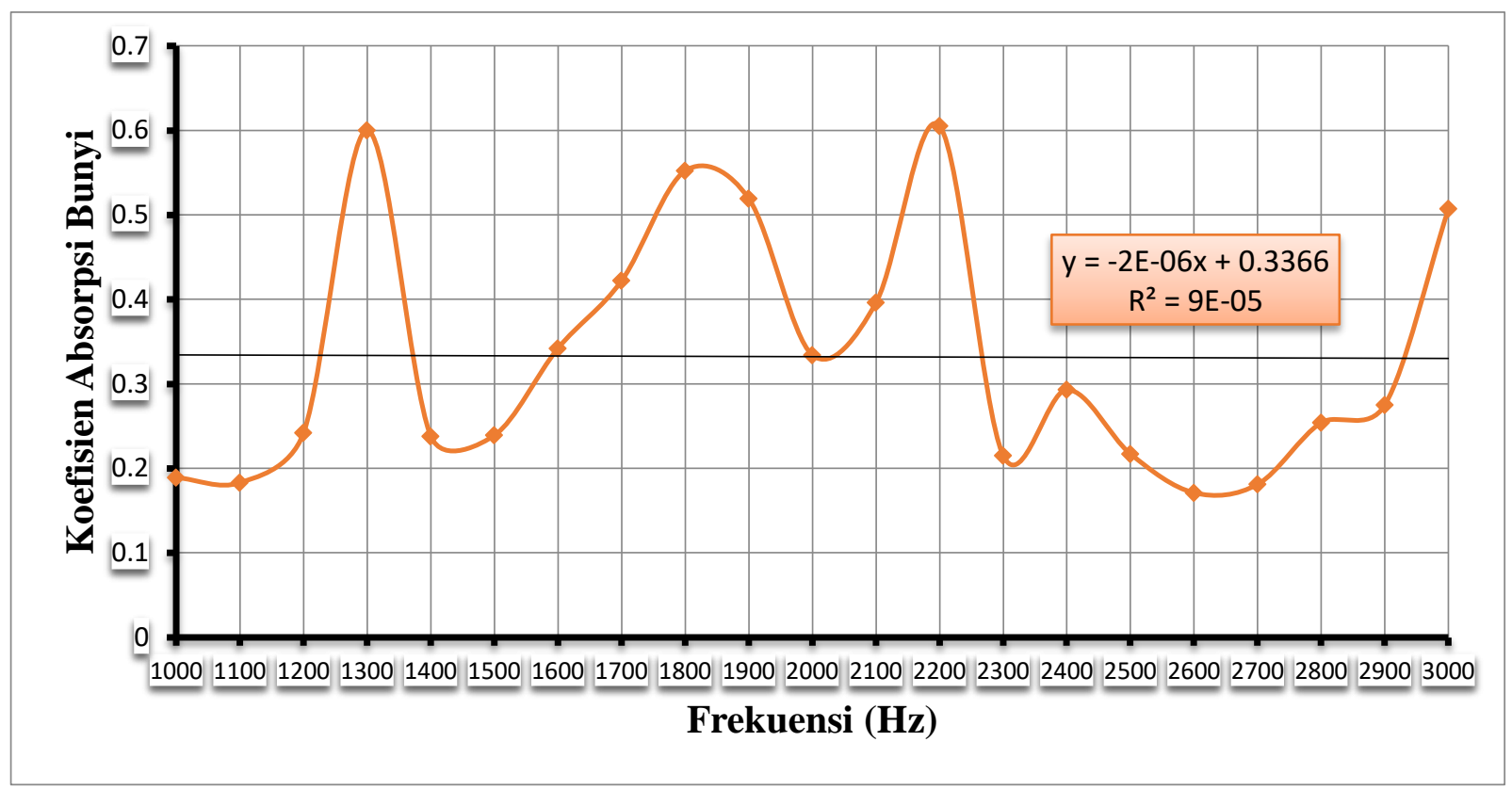

Gambar 5. Grafik Nilai Koefisien Absorpsi Bunyi Transmisi Pada Kayu Triplek

Berdasarkan data tabel nilai koefisien absopsi bunyi transmisi di atas maka di dapat hasil grafik dari bahan papan kayu dengan ketebalan $1 \mathrm{~cm}$ pada Gambar 6 sebagai berikut.

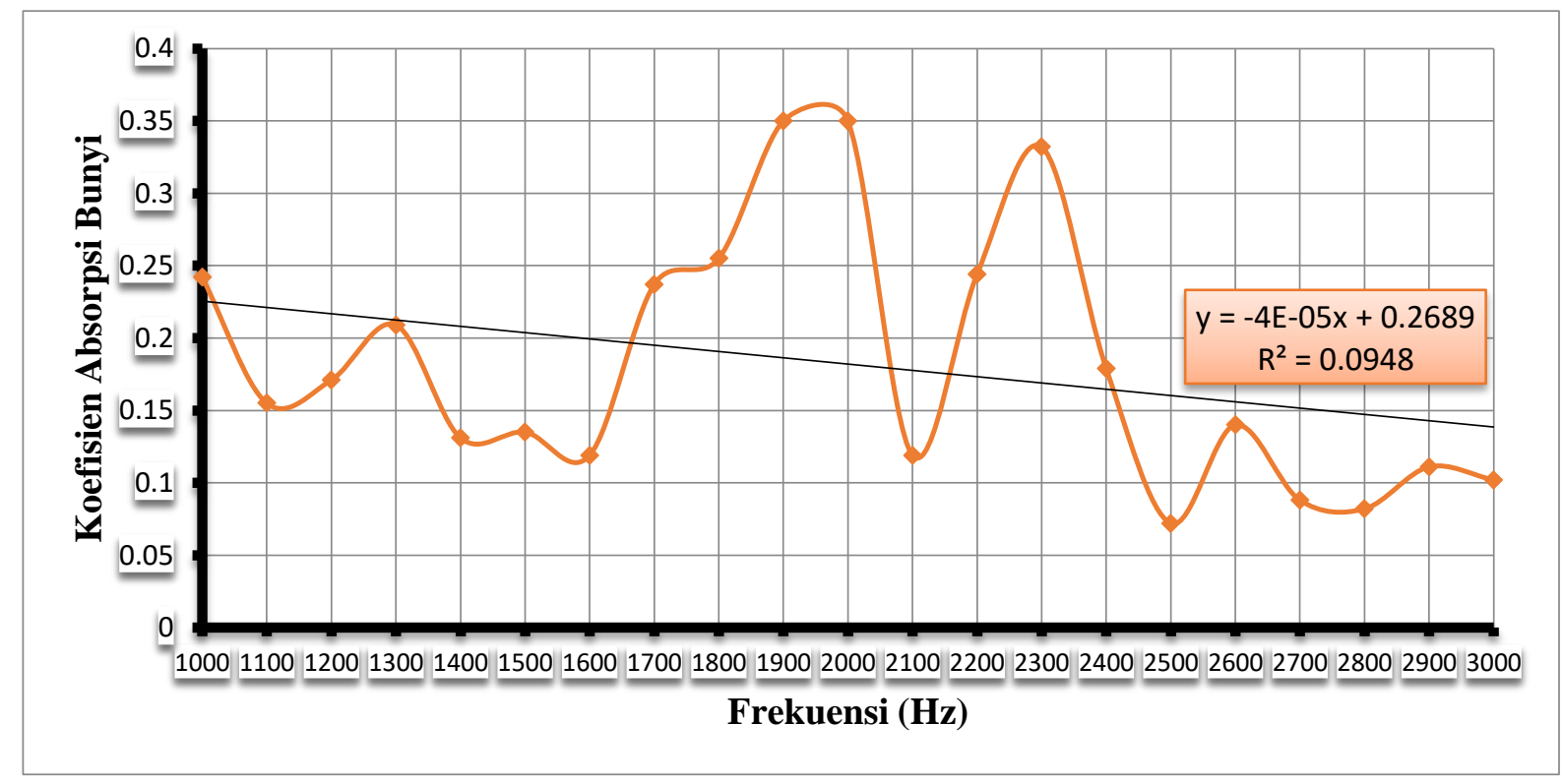

Gambar 6. Grafik Nilai Koefisien Absorpsi Bunyi Transmisi Pada Papan Kayu 
Berdasarkan data tabel nilai koefisien absopsi bunyi transmisi di atas maka di dapat hasil grafik dari bahan kalsiboard dengan ketebalan $0,4 \mathrm{~cm}$ pada Gambar 7 sebagai berikut.

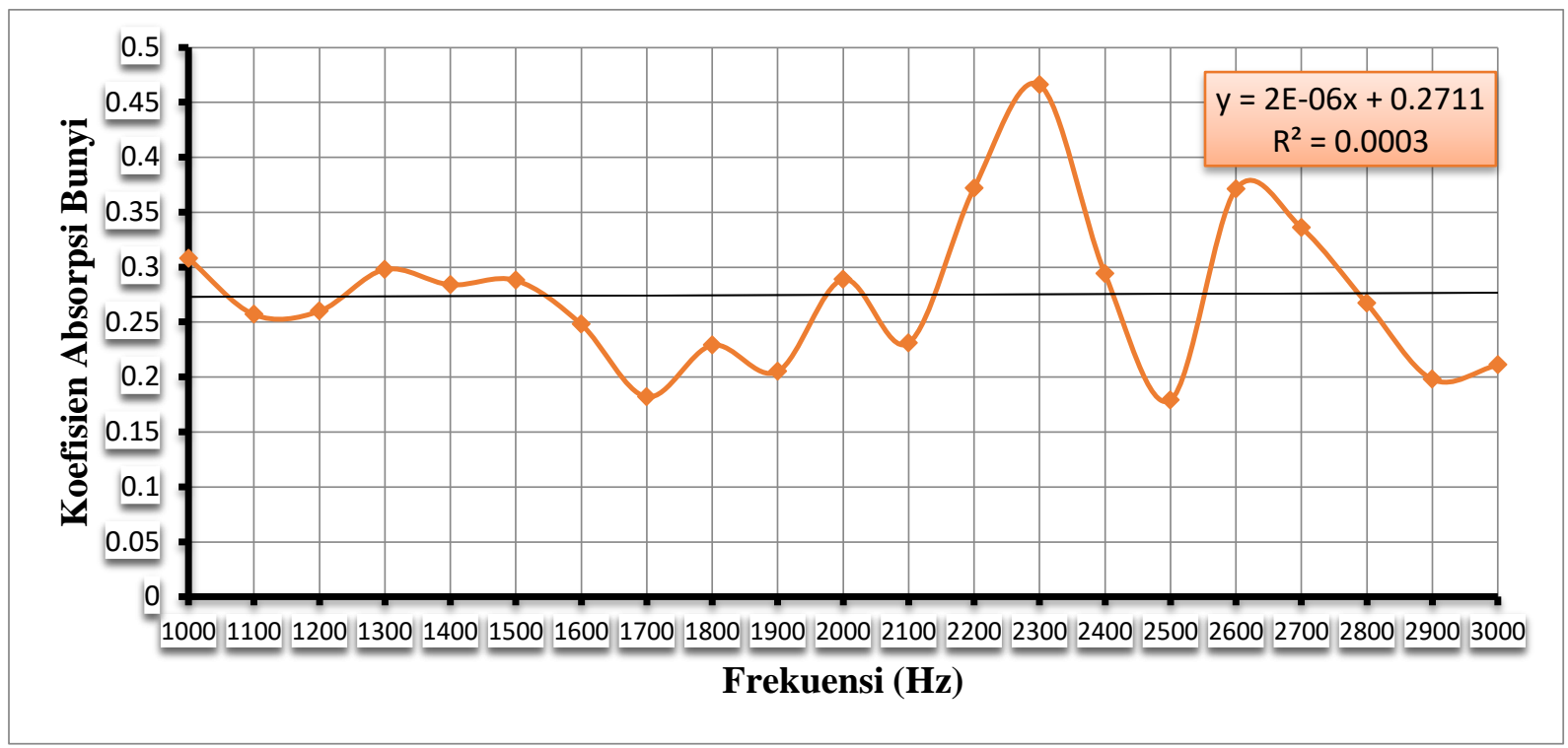

Gambar 7.Grafik Nilai Koefisien Absorpsi Bunyi Transmisi Pada Kalsiboard

Hasil penelitian koefisien absorpsi bunyi transmisi atau bunyi yang diteruskan setelah melewati bahan disajikan dalam bentuk grafik pada Gambar 5, Gambar 6 dan Gambar 7. Berdasarkan hasil grafik pada Gambar 5, Gambar 6 dan Gambar 7 dapat dilihat bahwa grafik yang menunjukkan puncak tertinggi merupakan nilai koefisien absorpsi bunyi tertinggi, sedangkan grafik yang menunjukkan penurunan merupakan hasil nilai koefisien absorpsi bunyi terendah pada hasil bunyi yang diteruskan. Hasil grafik pada Gambar 5 pada bahan triplek mempunyai nilai koefisien absorpsi bunyi transmisi tertinggi sebesar $0,605 \mathrm{~cm}^{-1}$ pada frekuensi sebesar $2200 \mathrm{~Hz}$, sedangkan untuk nilai koefisien absorpsi bunyi transmisi terendahnya sebesar $0,171 \mathrm{~cm}^{-1}$ pada frekuensi $2600 \mathrm{~Hz}$. Hasil grafik pada Gambar 6 pada bahan papan kayu mempunyai 2 puncak nilai koefisien absorbsi bunyi transmisi tertinggi dengan nilai yang sama yaitu sebesar $0,36 \mathrm{~cm}^{-1}$ pada frekunsi $1900 \mathrm{~Hz}$ dan $2000 \mathrm{~Hz}$, sedangkan untuk nilai koefisien absorpsi bunyi transmisi terendahnya sebesar $0,075 \mathrm{~cm}^{-1}$ pada frekuensi $2500 \mathrm{~Hz}$. Hasil grafik pada Gambar 7 pada bahan kalsiboard memilki nilai koefisien absorpsi bunyi transmisi tertinggi sebesar $0,466 \mathrm{~cm}^{-1}$ pada frekuensi $2300 \mathrm{~Hz}$, sedangkan untuk nilai koefisien absorpsi bunyi transmisi terendahnya sebesar $0,172 \mathrm{~cm}^{-1}$ pada frekusnsi sebesar $2500 \mathrm{~Hz}$.

Bunyi yang ditransmisikan atau bunyi yang diteruskan setelah melewati suatu bahan atau material tidak semua energi diteruskan, tetapi terdapat sebagian energi yang diserap. Berdasarkan penjelasan nilai koefisien absorpsi bunyi transmisi dari 3 bahan tersebut, dapat dilihat bahwa bahan yang mempunyai nilai koefisien absorpsi bunyi transmisi tertinggi yaitu, bahan triplek. Sedangkan untuk bahan yang mempunyai nilai koefisien absorpsi bunyi transmisi terendah yaitu, bahan papan kayu.

Bahan atau material dapat dikategorikan sebagai bahan penyerap bunyi yang baik apabila bahan atau material yang digunakan mempunyai nilai koefisien absorpsi bunyi sebesar $0,15 \mathrm{~cm}^{-}$ ${ }^{1}$ [1]. Berdasarkan uraian tersebut dapat dinyatakan bahwa dari 3 bahan yaitu, triplek, papan kayu dan kalsiboard, bahan yang dapat dikategorikan sebagai bahan penyerap bunyi yaitu triplek dan kalsiboard. Bahan triplek dan kalsiboard memiliki nilai koefisien absorpsi bunyi minimal diatas sebesar $0,15 \mathrm{~cm}^{-1}$ dan 2 bahan tersebut mempunyai ciri bahan yang lebih padat dibandingkan dengan papan kayu karena papan kayu bahannya sedikit berpori. 
Berdasarkan konsep hubungan antara koefisien absorpsi bunyi dengan frekuensi, jika nilai frekuensi besar maka nilai koefisien absorpsi bunyinya kecil begitu juga sebaliknya. Konsep tersebut jika diterapkan pada penelitian ini, dapat dilihat dari 3 bentuk grafik dan analisisnya bahwa nilai koefisien absorpsi bunyi terendah lebih cenderung pada frekuensi rendah dan nilai koefisien absorpsi bunyi tertinggi cenderung pada frekuensi tinggi. Sebenarnya jika dilihat secara keseluruhan besar dan kecilnya nilai koefisien absorpsi bunyi pada grafik tidak sejalan dengan kenaikan nilai frekuensi atau bisa dikatakan bahwa nilai koefisien absorpsi bunyi tidak ada hubungannya dengan nilai frekuensinya. Hal tersebut kemungkinan dipengaruhi oleh jenis bahan yang digunakan dan juga faktor-faktor seperti, tempat uji bahan yang belum memadai karena tidak menutupi keseluruhan bahan dan faktor lainnya yaitu alat yang belum dikalibrasi dengan baik. Pengaruh suara atau bunyi dari luar juga sangat mempengaruhi proses pengambilan data karena sifat SLM (sound level meter) yang sangat sensitif dengan bunyi atau suara dari luar. Umumnya nilai koefisien absorpsi bunyi akan optimum dan cenderung besar jika dilalui oleh suara yang frekuensinya lebih kecil dan begitu juga sebaliknya nilai koefisien absorpsi bunyi akan cenderung lebih kecil jika dilalui oleh suara yang frekuensinya lebih besar. Dalam penelitian ini tidak menggunakan variasi ketebalan pada setiap bahannya sehingga tidak berpengaruh terhadap nilai koefisien absorpsi bunyi.

\section{KESIMPULAN}

Nilai koefisien absorpsi bunyi transmisi tertinggi yaitu, pada bahan kayu triplek sebesar $0,605 \mathrm{~cm}^{-1}$ pada frekuensi $2200 \mathrm{~Hz}$ sedangkan nilai koefisien absorpsi bunyi transmisi terendah pada bahan papan kayu sebesar $0,075 \mathrm{~cm}^{-1}$ pada frekuensi $2500 \mathrm{~Hz}$. Hal tesebut disebabkan oleh karakteristik bahan kayu yang digunakan yaitu berpori dan tidak berpori atau padat. Bahan yang dapat dikategorikan sebagai bahan penyerap bunyi yaitu, kayu triplek dan kayu kalsiboard. Bahan triplek dan kalsiboard memiliki nilai koefisien absorpsi bunyi minimal diatas $0,15 \mathrm{~cm}^{-1}$.

\section{UCAPAN TERIMA KASIH}

Ucapan terima kasih penulis ucapkan kepada Ibu Dr. Pratiwi Sri Wardani, M.Kes dan Ibu Erlinda Ratnasari Putri, S.Si., M.Si. yang telah mendukung sehingga penelitian ini dapat diselesaikan.

\section{DAFTAR PUSTAKA}

[1] Thamrin, Suhaemi., Tongkukut, Seni H.J., As'ari. 2013. “Koefisien Serap Bunyi Papan Partikel Dari Bahan Serbuk Kayu Kelapa”. Jurnal MIPA UNSRAT. 2 (1). 56-57.

[2] Yuliantika, Sonya and Elvaswer. 2018. "Karakterisasi Koefisien Absorpsi Bunyi Dan Impedansi Akustik Dari Limbah Serat Kayu Meranti Merah (Shorea Pinanga) Dengan Menggunakan Metode Tabung”. Jurnal Ilmu Fisika (JIF). 10 (1). 31-32.

[3] Khotimah, Khusnul., Susilawati., Soeprianto, Harry. 2015. "Sifat Penyerapan Bunyi Pada Komposit Batang Pisang". Jurnal Penelitian Pendidikan IPA (JPPIPA). 1 (1). 93.

[4] Hurriyah. 2013. "Atenuasi Gelombang". Jurnal Eksakta. 2 (XIV). 39-41.

[5] Iksan, Khairatul. 2016. "Karakteristik Koefisien Absorpsi Bunyi dan Impendensi Akustik Dari Material Berongga Plafon PVC Menggunakan Metode Tabung Impedensi". TESIS Magester Bidang Fisika, Universitas ANDALAS. 
[6] Isranuri, Ikhwansyah and Asade, Felix. 2013. "Perancangan Tabung Impedansi dan Kajian Eksperimental Koefisien Serap Bunyi Paduan Aluminium-Magnesium". Jurnal eDinamis. 2 (6). 93.

[7] Eriningsih, Rifaidi., dkk. 2014. "Pembuatan Dan Karakterisasi Peredam Suara Dari Bahan Baku Serat Alam". Arena Tekstil. 29 (1). 1-8.

[8] Nisa', Ulatun. 2018. "Pembuatan Komposit Material Peredam Akustik Berbahan Dasar Dari Serat Sabut Kelapa, Pelepah Pisang, Lidah Mertua Dan Epoxy Resin". SKRIPSI Sarjana Pendidikan Fisika, Universitas Islam Negeri Walisongo.

[9] Suripto. 2016. “Uji Material Akustik Dari Serabut Nipah Menggunakan Metode Tabung Resonansi Dengan Variasi Ketebalan Sampel". SKRIPSI Sarjana Pendidikan MIPA Fisika, Institut Agama Islam Negeri Palangkaraya.

[10] Febrita, Vonny and Elvaswer. 2015. "Penentuan Koefisien Absorpsi Bunyi DanImpedansi Akustik Dari Serat Alam EcengGondok (Eichhornia Crassipes) DenganMenggunakan Metode Tabung". Jurnal IImu Fisika (JIF). 7 (2). 47. 